\title{
Kelembagaan Kelompok Wanita Tani Di Dusun Kedungpoh Kidul Desa Kedungpoh, Nglipar
}

\author{
Sriyadi (1), Jazaul Ikhsan (2) \\ (1) Program Studi Agribisnis Fakultas Pertanian Universitas Muhammadiyah Yogyakarta, \\ (2) Program Studi Teknik Sipil Fakultas Teknik Universitas Muhammadiyah Yogyakarta \\ Jl. Brawijaya, Tamantirto, Kasihan, Bantul, Yogyakarta \\ Email : sriyadi_s@yahoo.co.id \\ DOI: $10.18196 / p p m .32 .225$
}

\begin{abstract}
Dusun Kedungpoh Kidul terletak di Desa Kedungpoh, Kecamatan Nglipar, Kabupaten Gunungkidul, Daerah Istimewa Yogyakarta. Dusun Kedungpoh Kidul terdiri atas 4 Rukun Tetangga, 1 Rukun Warga, dan 101 Kepala Keluarga. Dusun Kedungpoh Kidul dipimpin oleh seorang kepala dukuh yang dalam membangun pedukuhannya didukung Kelompok Kegiatan Lembaga Pemberdayaan Masyarakat Desa (POKGIAT LPMD), Pemberdayaan Kesejahteraan Keluarga Tingkat Pedukuhan (PKK Dusun), Karang Taruna, Kelompok Tani, Kelompok Wanita Tani, Posyandu Anak, Posyandu Lansia, dan Takmir Masjid. Mata pencaharian penduduk Dusun Kedungpoh Kidul sebagian besar merupakan petani, buruh, pedagang, pengrajin, dan beberapa menjadi Pegawai Negeri Sipil. Berdasarkan pemetaan secara partisipatif dengan masyarakat, permasalahan yang dihadapi masyarakat di Dusun Kedungpoh Kidul adalah Kelompok Wanita Tani (KWT) Lantip Makarti belum berfungsi secara maksimal. Solusi yang ditawarkan (1) penyuluhan pengembangan organisasi, (2) penyuluhan pembuatan pupuk kompos, (3) penyuluhan budi daya Aloe Vera, (4) penyuluhan pengolahan Aloe Vera, serta (5) penyuluhan dan pembagian bibit tanaman. Hasil pengabdian menunjukkan penyuluhan pengembangan organisasi, penyuluhan pembuatan pupuk kompos, penyuluhan budi daya Aloe Vera, penyuluhan pengolahan Aloe Vera, dan penyuluhan dan pembagian bibit tanaman terlaksana dengan baik dan diikuti dengan antusias oleh masyarakat. Perlu pendampingan oleh pemerintah dan perguruan tinggi secara berkesinambungan demi berhasilnya program Kelompok Wanita Tani (KWT) Lantip Makarti.
\end{abstract}

Kata kunci; kelembagaan, kelompok tani wanita, dan organisasi.

\section{PENDAHULUAN}

Dusun Kedungpoh Kidul merupakan 1 dari 10 dusun yang ada di Desa Kedungpoh, Kecamatan Nglipar, Kabupaten Gunungkidul. Dusun Kedungpoh Kidul terdiri atas 4 RT, 1 RW, $101 \mathrm{KK}$ dengan jumlah penduduk 368 jiwa. Sebagian besar penduduk merupakan petani. Salah satu usaha untuk meningkatkan kesejahteraan masyarakat adalah dengan pengelolaan usaha tani secara baik dan intensif. Agar pengelolaan usaha tani lebih baik lagi perlu penguatan kelembagaan kelompok wanita tani sehingga informasi dan teknologi pertanian tersampaikan kepada petani.

Mulyana (2000) menjelaskan kelompok adalah sekumpulan orang yang mempunyai tujuan bersama yang berinteraksi satu sama lain untuk tercapainya tujuan bersama. Johnson dan Johnson (2012) mendefinisikan kelompok adalah himpunan dua individu atau lebih yang berinteraksi melalui tatap muka dan masing-masing menyadari peran keanggotaannya dalam kelompok. Winardi (2003) mengemukakan bahwa yang menjadi ciri kelompok adalah 1) ada interaksi antaranggota; 2) setiap anggota menyadari bahwa mereka merupakan bagian dari kelompok; 3) adanya kesepakatan bersama antaranggota mengenai norma-norma yang berlaku; 4) adanya struktur dalam kelompok.

Kelompok Tani menurut Mardikanto (1993) diartikan sebagai kumpulan orang-orang tani. Kelompok Wanita Tani menurut Kartini (200) adalah kumpulan yang terdiri atas dua orang atau lebih individu dan kehadiran masing-masing individu mempunyai arti serta nilai bagi orang lain dan berada dalam situasi saling memengaruhi. Suhardiyono (1992) menyatakan untuk meningkatkan dinamika kelompok tani harus dikembangkan 10 jenis kemampuan kelompok tani 
yang disebut dengan 10 jurus kemampuan kelompok tani yang terdiri atas a) menyusun rencana kerja kelompok tani, b) kerja sama intern kelompok tani, c) menerapkan teknologi baru, d) memecahkan masalah kelompok serta mengatasi kondisi darurat, e) pemupukan modal usaha, f) kemampuan mengembangkan peralatan dan fasilitas kelompok, g) menjalin hubungan lembaga dengan KUD, perbankan, dan instansi terkait, h) peningkatan produktivitas usaha tani, i) ketaatan atas perjanjian, dan j) membina kader pimpinan kelompok.

Berdasarkan pemetaan secara partisipatif dengan masyarakat, permasalahan yang dihadapi masyarakat di Dusun Kedungpoh Kidul, Desa Kedungpoh, Kecamatan Nglipar, Kabupaten Gunungkidul adalah Kelompok Wanita Tani Lantib Makarti yang belum berfungsi secara maksimal. Berdasarkan permasalahan tersebut, tujuan dari pengabdian ini antara lain 1) mengetahui manajemen Kelompok Wanita Tani Lantib Makarti dan 2) mengetahui potensi Kelompok Tani Lantib Makarti.

\section{METODE PELAKSANAAN}

Sasaran umum dari pengabdian ini adalah seluruh masyarakat di wilayah Dusun Kedungpoh Kidul, Desa Kedungpoh, Kecamatan Nglipar, Kabupaten Gunungkidul, tetapi kelompok sasaran yang terlibat langsung dalam kegiatan adalah Ibu-ibu Kelompok Wanita Tani Lantib Makarti di Dusun Kedungpoh Kidul, Desa Kedungpoh, Kecamatan Nglipar, Kabupaten Gunungkidul.

Masalah yang dihadapi oleh Kelompok Wanita Tani Lantib Makarti akan diselesaikan dengan pemberdayaan melalui pelatihan, fasilitasi, dan pendampingan berupa :

1. Penyuluhan pengembangan organisasi beserta pendampingannya

2. Penyuluhan manajemen administrasi beserta pendampingannya.

3. Penyuluhan pembuatan pupuk kompos beserta pendampingannya

4. Penyuluhan budi daya Aloe Vera beserta pendampingannya

5. Penyuluhan pengolahan Aloe Vera beserta pendampingannya, dan

6. Penyuluhan dan pembagian bibit tanaman.

\section{HASIL DAN PEMBAHASAN}

\section{Penyuluhan Pengembangan Organisasi}

Pada acara penyuluhan pengembangan organisasi kelompok wanita tani, pematerinya adalah Ryan Aji Nugroho dan tim kelompok KKN 078 UMY. Kegiatan ini dilaksanakan pada tanggal 18 Januari 2020, pukul 07.30 - 11.30, di Balai Dusun Kedungpoh Kidul dan dihadiri 35 orang, baik pengurus maupun anggota kelompok wanita tani. Kegiatan ini disambut dengan penuh antusias oleh para ibu-ibu dan anak remaja. Hal ini ditunjukkan ibu-ibu anak anak remaja yang mengikuti acara tersebut sangat antusias dalam menanyakan beberapa pertanyaan yang membingungkan. 


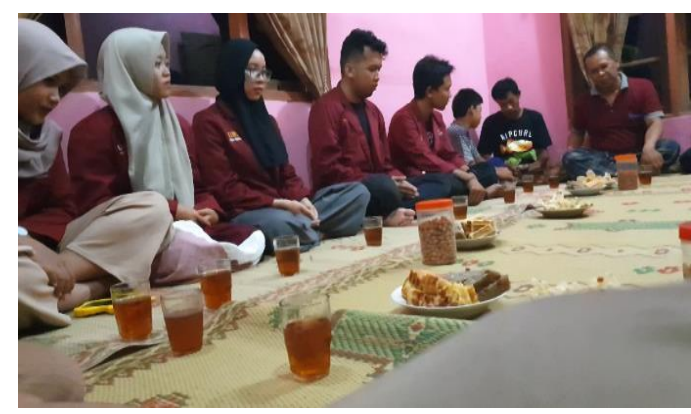

Gambar 1. Sosialisasi Pentingnya Organisasi dan Pengelolaannya.

\section{Penyuluhan Manajemen Administrasi}

Pada acara penyuluhan manajemen administrasi kelompok wanita tani, sebagai pematerinya adalah Dr. Sriyadi dan tim kelompok KKN 078 UMY. Kegiatan ini dilaksanakan pada tanggal 21 Januari 2020, pukul 07.30 - 11.30, bertempat di Balai Dusun Kedungpoh Kidul., dan dihadiri 35 orang, baik pengurus maupun anggota kelompok wanita tani. Materi yang disampaikan adalah berkaitan dengan administrasi atau pencatatan. Dalam hal ini, pemateri menjelaskan tujuan, kegunaan, dan cara melakukan administrasi yang baik dan benar. Kami juga menunjukkan contoh surat menyurat secar resmi, pembuatan proposal, serta melakukan pencatatan keuangan. Kegiatan ini sangat disambut dengan penuh antusias. Bahkan, ada seorang ibu bertanya mengenai surat-menyurat resmi dan proposal.

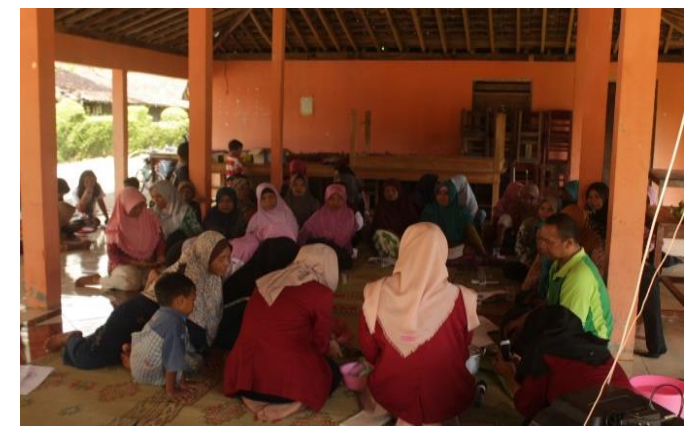

Gambar 2. Penyuluhan dan Pelatihan Manajemen Organisasi, Administrasi dan Keuangan Kelompok Wanita Tani

\section{Penyuluhan Pembuatan Pupuk Kompos}

Penyuluhan pembuatan pupuk kompos ini dilaksanakan pada tanggal 10 Januari 2020 berlokasi di Balai Dusun Kedungpoh Kidul dan dilanjutkan dengan praktik pembuatan pupuk kompos. Pemateri dari program ini adalah Dinda Aishah Rifani, mahasiswa pertanian dan tim kelompok KKN 078 UMY. Tujuan dari penyuluhan ini untuk memberikan informasi tentang cara membuat pupuk kompos dan praktk membuatnya. Target peserta yang diharapkan ikut berpartisipasi sebanyak 30 orang, tetapi yang hadir 26 orang. Kelancaran program ini sangat terbantu dengan antusiasnya para ibu-ibu kelompok wanita tani dalam memerhatikan materi yang disampaikan, praktik yang telah dilakukan, dan proses tanya jawab yang aktif. 


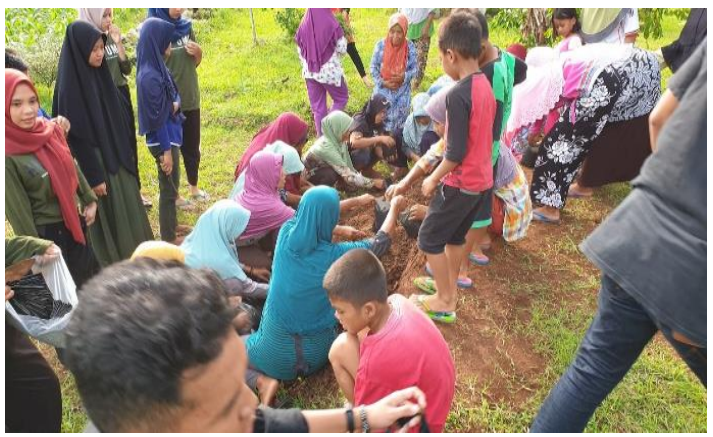

Gambar 3. Penyuluhan Pembuatan Pupuk Kompos

\section{Penyuluhan Budidaya Aloe Vera}

Penyuluhan budi daya Aloe Vera ini dilaksanakan pada tanggal 24 Januari 2020, berlokasi di Balai Budaya Kedungpoh Kidul dan dilanjutkan praktik budi daya Aloe Vera. Penyuluhan ini diiikuti sebanyak 50 orang. Tujuan dari kegiatan ini ialah agar masyarakat dapat mengetahui dan paham tentang cara menanam dan merawat tanaman Aloe Vera. Kelancaran program ini sangat terbantu dengan antusiasnya warga masyarakat dalam memerhatikan materimateri yang disampaikan oleh pemateri dan aktifnya warga dalam melakukan tanya jawab. Materi yang disampaikan adalah budi daya sampai paskapanen aloe vera. Dalam penyuluhan ini, pemateri menyampaikan cara membudi dayakan Aloe Vera dengan benar. Materi disampaikan oleh peneliti dan tim kelompok KKN 078 UMY.

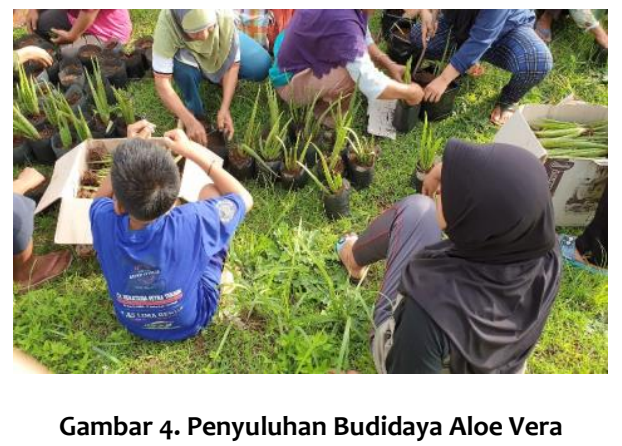

\section{Penyuluhan Pengolahan Aloe Vera}

Setelah melakukan penyuluhan mengenai cara menanam bibit Aloe Vera yang baik dan benar, peneliti dan tim Kelompok KKN 078 UMY juga mempraktikkan mengenai cara mengolah Aloe Vera, mulai dari pemotongan saat panen hingga cara mengolahnya menjadi minuman sederhana yang segar dan dengan harga yang terjangkau. Tujuan diadakannya penyuluhan pengolahan Aloe Vera ini agar ibu-ibu rumah tangga dapat menambah penghasilan sehingga mampu membantu dalam memenuhi kebutuhan sehari-hari. Selain itu, penyuluhan pengolahan Aloe Vera ini diharapkan bisa menjadi home industri di wilayah Kedungpoh Kidul dan dapat menjadi sentra pengolahan tanaman Aloe Vera. Ibu-ibu sangat antusias dan mengantre agar dapat mempraktikkan cara mengupas dan memotong batang Aloe Vera. Setelah program penyuluhan pengolahan Aloe Vera terlaksana di Balai Dusun Kedungpoh Kidul dan dilanjutkan praktik pengolahan Aloe Vera menjadi minuman segar. Beberapa ibu langsung mencoba mempraktikkan kembali di rumahnya masing-masing. 


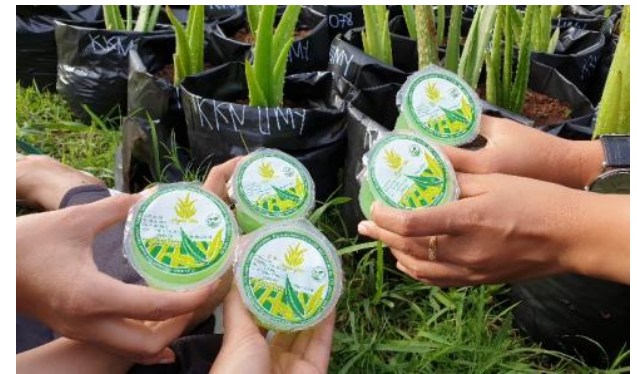

Gambar 5. Penyuluhan Pengolahan Aloe Vera

\section{Penyuluhan dan Pembagian Bibit Tanaman}

Penyuluhan dan pembagian bibit tanaman durian dan alpukat dilakukan oleh peneliti dan tim Kelompok KKN 078 UMY. Pemateri dalam penyuluhan tentang tata cara menanam durian dan alpukat adalah Dr. Sriyadi dibantu oleh tim Kelompok KKN 078 UMY. Di samping penyuluhan tentang tata cara budi daya durian dan alpukat, pada kesempatan ini, juga dibagikan bibit pohon durian dan pohon alpukat. Penyuluhan dan pembagian bibit tanaman durian dan alpukat bertujuan agar masyarakat dapat mendapatkan hasil dari tanaman yang mereka tanam. Kegiatan ini dilaksanakan pada hari rabu, 5 Februari 2020 pada pukul 08.00 - 10.30 bertempat di Balai Dusun Kedungpoh Kidul. Penyuluhan dan pembagian bibit tanaman durian dan alpukat dihadiri oleh Lurah Desa Kedungpoh, Kadus Dusun Kedungpoh Kidul, dan pengurus dan anggota kelompok wanita tani yang ada di Pedukuhan Kedungpoh Kidul sebanyak 100 orang. Pada kesempatan ini, dibagikan kepada masyarakat berupa bibit tanaman durian dan bibit tanaman alpukat sebanyak 100 bibit tanaman durian dan bibit alpukat.

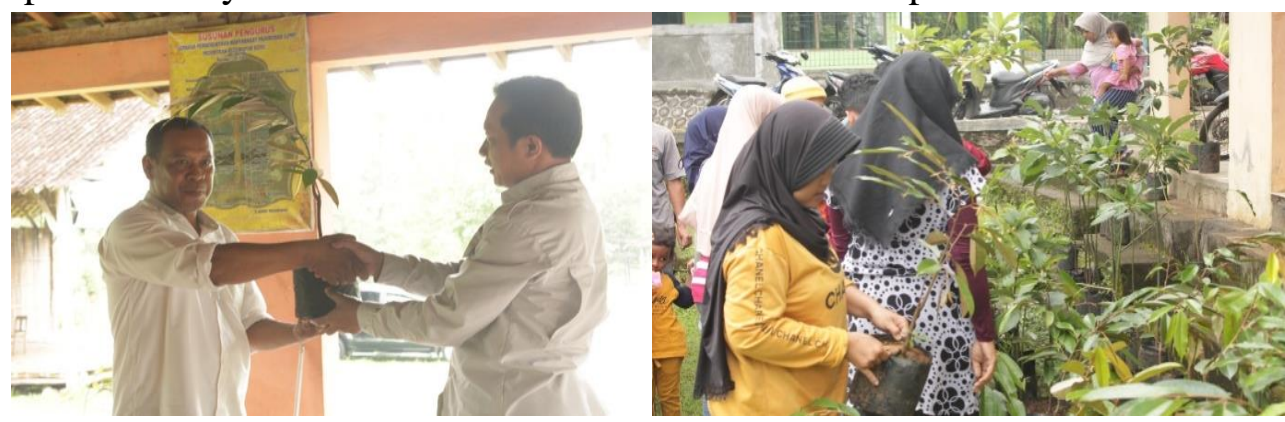

Gambar 6. Penyuluhan dan Pembagian Bibit Tanaman

\section{KESIMPULAN DAN SARAN}

\section{Kesimpulan}

Pengabdian telah selesai dilaksanakan dengan baik. Ada beberapa hal yang dapat disimpulkan, yaitu

1. Terlaksananya penyuluhan pengembangan organisasi, penyuluhan manajemen administrasi, penyuluhan pembuatan pupuk kompos, penyuluhan budi daya Aloe Vera, penyuluhan pengolahan Aloe Vera, serta penyuluhan dan pembagian bibit tanaman.

2. Semua kegiatan diikuti dengan antusias oleh ibu-ibu pengurus dan anggota Kelompok Wanita Tani Lantib Makarti. 


\section{Saran}

Perlu pendampingan oleh pemerintah dan perguruan tinggi yang berkesinambungan demi berhasilnya program Kelompok Wanita Tani Lantib Makarti.

\section{UCAPAN TERIMA KASIH}

1. Rektor UMY yang telah memberikan kesempatan melakukan pengabdian pada masyarakat.

2. LP3M UMY yang mendanai hibah Pengabdian pada masyarakat Program Peningkatan Tri Dharma Perguruan Tinggi Tahun 2019/2020.

\section{DAFTAR PUSTAKA}

Kartini Kartono. Pemimpin dan Kepemimpinan: Apakah Kepemimpinan Abnirmal Itu , Jakarta: Rajawali Pers, 2009

Mardikanto, T. 1993. Penyuluhan Pembangunan Pertanian. Surakarta: UNS Press.

Mulyana, 2000. Ilmu Komunikasi Suatu Pengantar. Jakarta:PT Remaja Rosdakarya.

Peraturan Menteri Pertanian (On-line), tersedia di : https:// kelembagaan das. Word press. com/ kelembagaan-petani/peraturan-menteri-pertanian.htm (13 April 2007)

Suhardiyono, L. 1992. Petunjuk Bagi Penyuluhan Pertanian. Jakarta: Erlangga.

W. David Johnson, 2012. Dinamika Kelompok (Teori dan Ketrampilan), Jakarta : PT Indeks

Winardi, J, 2003. Teori Organisasi dan Pengorganisasian, Jakarta: PT Raja rafindo

Persada 